\title{
Clinical Management of Post-partum total uterine prolapse following excessive traction during delivery of kid in a Non- Descript Goat
}

\author{
A. Senthilkumar \\ Tamilnadu Veterinary and Animal Sciences University \\ Assistant Professor and Head,Farmers Training Centre,Theni-625 531,Tamilnadu India
}

\begin{abstract}
A post-partum total uterine prolapse in a 3 years old non-descript goat was presented. This paper reports a clinical management of the case. The everted uterus was carefully assessed and gross debris gently removed and disinfected with dilute chlorhexidine solution. Epidural anaesthesia was achieved using $2 \mathrm{ml}$ of $2 \%$ lignocaine solution administered at the intercoccygeal joint. The prolapsed uterus was replaced and no suture was placed on the vulva. Oxytocin, calcium borogluconate, broad-spectrum antibiotics (ceftriaxone) and DNS solution were administered. The animal was completely recovered.
\end{abstract}

Keywords: Clinical, Doe, Management, Post-partum, Uterine, Prolapse

\section{Introduction}

Uterine prolapse has been recorded in all animal species. It is most common in the cow and ewe, less common in the doe and rare in the mare (1) and is an emergency condition which needs prompt and immediate attention (2). It is simply an eversion of the uterus which turns inside out asit passes through the vagina. Prolapse of the uterus generally occurs immediately after or a few hours of parturition when the cervix is open and the uterus lacks tone (3). Prolapse that occur more than 24 hours post-partum is extremely rare and is complicated by partial closure of the cervix, making replacement difficult or even impossible (4). In the period immediately after prolapsed occurs the tissues appear almost normal, but within a few hours they become enlarged and edematous. Some animals will develop hypovolaemic shock secondary to internal blood loss, laceration of the prolapsed organ or incarceration of abdominal viscera (5).The prolapse is visible as a large mass protruding from the vulva, often hanging down below the animal's hock. The placenta may likely be retained during this period (6). It normally occurs during the third stage of labour at a time when the fetus has been expelled and the fetal cotyledons have separated from the maternal caruncles (2). The etiology of uterine prolapse is unknown, But many factors have been associated with prolapse (7) and (3). These includes conditions such as poor uterine tone, Increased straining caused by pain or discomfort after parturition. Excessive traction at assisted parturition. The weight of retained fetal membranes. Conditions that increased intra-abdominal pressure including tympany and excessive estrogen content in the feed. Animals with uterine prolapse treated promptly recovers without complication while delay treatment could result in death of the animal in a matter of hour or so from internal haemorrhage caused by the weight of the organ which tears the mesovarium and artery (2). Success of treatment depends on the type of case, the duration of the case, the degree of damage and contamination. This paper focuses on the clinical case presented and it high lighted the clinical management of total uterine prolapse in small ruminant (Doe) which occurred after forceful delivery of kid in a non descript goat.

\section{Case History And Observations}

A non descript goat on its first kidding was brought to field veterinarian with the history of having one live kid with forceful delivery by non veterinarian today afternoon. After delivery the animal had continuous straining and the uterus was prolapsed after three hours of delivery. At the time of observation, the animal was dull and depressed. The clinical examination of the animal showed a pale visible mucus membranes, body temperature $38.9^{\circ} \mathrm{C}$, heart rate $88 / \mathrm{min}$, respiratory rate of $22 / \mathrm{min}$ and grinding of teeth. The fetal membranes were tightly adhered over the caruncles which was soiled and inflamed.

\section{Treatment And Discussion}

The goat was administered $1.5 \mathrm{ml}$ of $2 \%$ lignocaine at first coccygeal space to attain epidural anaesthesia. The prolapsed uterus was gently washed and disinfected with dilute chlorhexidine solution (8) and the foetal membranes were separated manually from the maternal caruncles. The urine was relieved from bladder by catheter. The mass was washed with saturated salt solution to reduce the edema again washed with $1 \%$ potassium permanganate solution. The cetrimide cream was liberally applied over the mass. The hind 
portion of the animal was elevated by folding the hind limbs at the level of hock joint. The vulval lips were pulled apart and the everted mass was reduced using the palm of both the hands. The proper replacement was ensured by introducing the hand through the cervix and no vulval retention suture was applied. Once the uterus is replaced, the operators hand should be inserted to the tip of both uterine horns to be sure that no remaining invagination could incite abdominal straining and reprolapse (4). If the uterusis completely and fully replaced all the way to the tips ofthe uterine horns, the prolapse is unlikely to occur (3). The animal was administered inj.Calcium borogluconate $(75 \mathrm{ml}$, slow i/v), inj.Oxytocin (10 IU,i/v), inj.DNS (400 ml,i/v), inj. ceftriaxone (200 $\mathrm{mg}, \mathrm{i} / \mathrm{m})$ and inj.Chlorpheniramine maleate $(30 \mathrm{mg}, \mathrm{i} / \mathrm{m})$. The antibiotic and antihistamine was continued for three days and animal recovered uneventfully. Prolapse of the uterus normally occur during the third stage of labour at a time when the fetus has been expelled and the fetal cotyledons has separated from the maternal caruncles (2). In small animals, complete prolapse of both uterine horns is usual ( (9); (10)) and But in the present case prolapsed of uterus was observed after forceful delivery of kid. The goal in the treatment of uterine prolapsed is replacement of the organ followed by a method to keep it in a retained position. Once the uterus is in its normal position, oxytocin $10 \mathrm{i}$.u intramuscularly should be administered to increase uterine tone. It has also been reported that most animals with uterine prolapse are hypocalcaemic (4). Where signs of hypocalcaemia are noticed such animals should therefore, be given calciumborogluconate. An injectable broad spectrum antibiotics once administered for three to five days after replacement of the prolapsed will prevent secondary bacterial infection $(8 ; 11$; and 12$)$.

\section{References}

[1]. S.J.Roberts , Injuries and Diseases of the Puerperal Period", in S J Roberts (Ed.), Veterinary Obstetrics and Genital Diseases, 3rd Edition, (Vermont, Woodstock,1986) 353-397.

[2]. D E, Noakes, T.J. Perkinson and G.C. W. England, Post Parturient Prolapse of the Uterus, in Arthur's Veterinary Reproductionand Obstetrics, (Saunders,2001), 333-338,

[3]. E.A. Hanie, Prolapse of the Vaginal and Uterus in Text Book of Large Animal Clinical Procedures for Veterinary Technicians", (Elsevier, Mosby,2006), 218-221.

[4]. S. L. Fubini and G. N. Ducharme),Surgical Conditions of the Post PartumPeriod in Text Book of Farm Animal Surgery, (2006), 333-338.

[5]. T. Potter, (2008), Prolapse of the Uterus in the Cow, UK Veterinary Journal, 13,2008, 1-3.

[6]. S. J. Roberts, Injuries and Diseases of the Puerperal Period in Text Book of Veterinary Obstetrics and Genital Diseases, (Indian Edn.1982), 300-340.

[7]. P. G. G. Jackson, Post parturient Problems in Large Animals in Hand Book of

[8]. Veterinary Obstetrics, 2nd Edition,(Elsevier Saunders.2004), 209-231.

[9]. B.Hosie, Treatment of Vaginal Prolapse in Ewes, Practice, 15,1993,10-11.

[10]. P. G. Jackson, Post parturient Problems in Large Animals, in P.G.Jackson (Ed.), Handbook of Veterinary Obstetrics,2nd Edition, (WB Saunders,London ,1995),209-232.

[11]. I.B.Munro,, Replacing the Prolapsed Bovine Uterus, Veterinary Record, 155,2004, 344.

[12]. S. J. Plunkett (2000), Vaginal Edema (Hyperplasia) or Prolapse and Uterine Prolapse in Text Book of Emergency Procedure for the Small Animal Veterinarian, (WB aunders.2000),217-218

[13]. J.Borobia-Belsue, (2006), Replacement of Rectal Prolapsein Sows, Vet. Rec., 19,2006, 380.

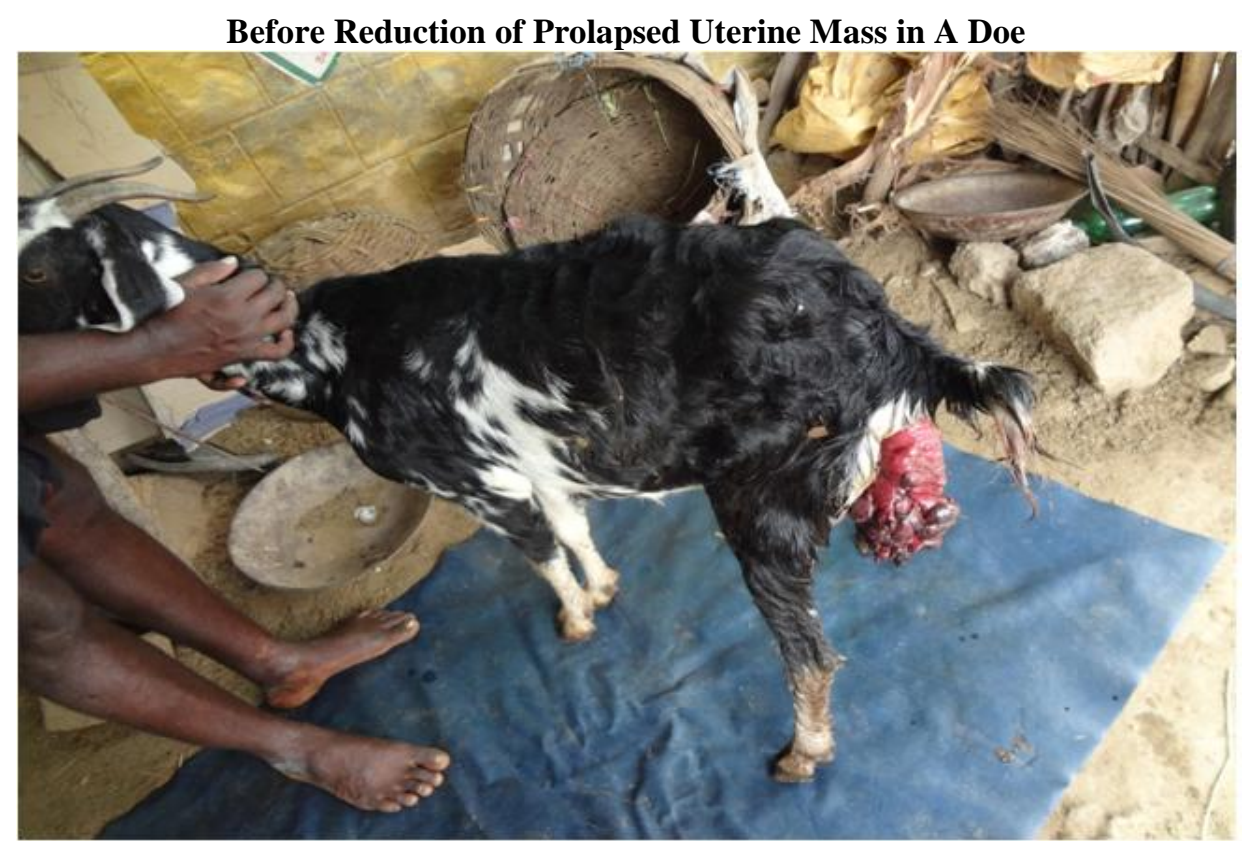


Clinical Management of Post-partum total uterine prolapse following excessive traction ....

After Reduction Of Prolapsed Uterine Mass In A Doe

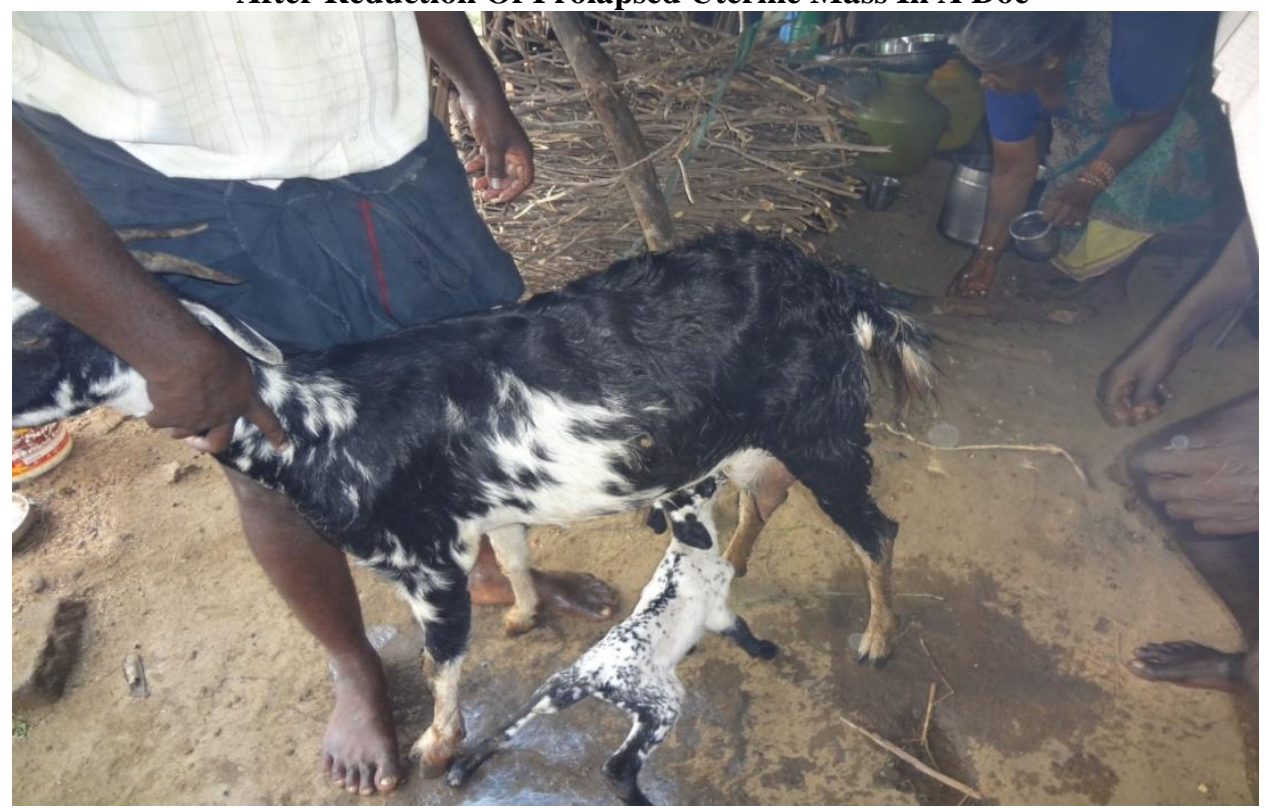

